\begin{tabular}{|c|c|c|c|c|c|c|}
\hline \multirow{4}{*}{ Impact Factor: } & ISRA (India) & $=\mathbf{3 . 1 1 7}$ & SIS (USA) & $=0.912$ & ICV (Poland) & $=6.630$ \\
\hline & ISI (Dubai, UAI & $=0.829$ & РИНЦ (Russia) & $=0.156$ & PIF (India) & $=1.940$ \\
\hline & GIF (Australia) & $=0.564$ & ESJI (KZ) & $=8.716$ & IBI (India) & $=4.260$ \\
\hline & JIF & $=1.500$ & SJIF (Morocco & $=5.667$ & OAJI (USA) & $=0.350$ \\
\hline
\end{tabular}

\section{SOI: $1.1 /$ TAS $\quad$ DOI: $10.15863 /$ TAS International Scientific Journal Theoretical \& Applied Science}

p-ISSN: 2308-4944 (print) $\quad$ e-ISSN: 2409-0085 (online)

Year: $2019 \quad$ Issue: $05 \quad$ Volume: 73

Published: 30.05 .2019 http://T-Science.org

SECTION 5. Innovative technologies in science. UDC 677.21:021
QR - Issue

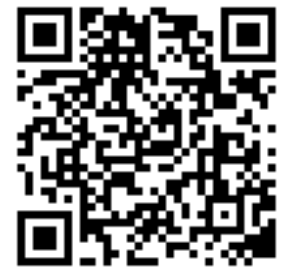

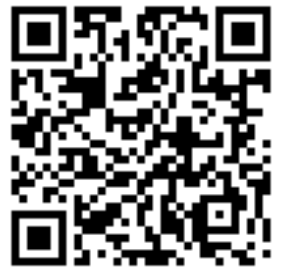

S. Xashimov Docent,

Namangan Engineering - Construction Institute

N. Abdullayeva senior teacher,

Namangan Engineering - Construction Institute

M. Dadamirzayev senior teacher,

Namangan Engineering - Construction Institute

G. Rizamuhamedova senior teacher,

Namangan Engineering - Construction Institute

\title{
INTRODUCTION OF A COTTON CLEANING DEVICE FOR TECHNICAL AND TECHNOLOGICAL RE-EQUIPMENT, MODERNIZATION THE COTTON CLEANING INDUSTRY IN UZBEKISTAN
}

\begin{abstract}
Today, Uzbekistan is considered the sixth largest producer state in producing one million tons of cotton fiber. It is known that the process of collecting cotton manually before it is taken to plants also affects the quality of cotton fiber. As a result, there are various problems in the processing of cotton, especially the cleaning of cotton from dirt. On the one hand, when cotton is cleaned by CCE (Cotton cleaning equipment) from coarse and fine contaminants, cotton is almost cleaned of contaminants (the positive side of existing technologies), on the other hand, there is a separation of pieces of cotton into smaller parts of this piece(the negative side of existing technologies). Just this side of technology that reduces the quality of fiber that does not meet today's requirements. At the same time we have developed devices for cleaning cotton, which make it possible to improve the quality of the fiber. One feature of this technology is that because of the flow of movement, pieces of cotton in the device, directed from top to bottom, due to the inertia of its movement, unnecessary impurities in the cotton composition, moving from top to bottom in the sieve section (the method of separating cotton), existing muds are quickly allocated and improved by cleansing of cotton. The network surface of the cotton gin cleaning device that performs the task of the separator separates the pieces of seed cotton in stages, and through the small openings of the network there is not cotton, but pollution in its composition. As a result, cotton pieces are cleaned, and the natural state of cotton is preserved, and the quality of the resulting fiber is improved.

Key words: Cotton from seed; raw cotton; fiber quality; cotton cleaning equipment; improvement of cotton cleaning device; cotton ginning plants; choice of cotton cleaning technology; contamination of seed cotton.

Language: Russian

Citation: Xashimov, S., Abdullayeva, N., Dadamirzayev, M., \& Rizamuhamedova, G. (2019). Introduction of a cotton cleaning device for technical and technological re-equipment, modernization the cotton cleaning industry in Uzbekistan. ISJ Theoretical \& Applied Science, 05 (73), 536-540.

Soi: http://s-o-i.org/1.1/TAS-05-73-82 Doi: crossef https://dx.doi.org/10.15863/TAS.2019.05.73.82

\section{ВНЕДРЕНИЕ ХЛОПКООЧИСТИТЕЛЬНОГО УСТРОЙСТВА ДЛЯ ТЕХНИЧЕСКОГО И ТЕХНОЛОГИЧЕСКОГО ПЕРЕОБОРУДОВАНИЯ, МОДЕРНИЗАЦИИ ХЛОПКООЧИСТИТЕЛЬНОЙ ПРОМЫШЛЕННОСТИ В УЗБЕКИСТАНЕ}




\begin{tabular}{|c|c|c|c|c|c|c|}
\hline \multirow{4}{*}{ Impact Factor: } & ISRA (India) & $=3.117$ & SIS (USA) & $=0.912$ & ICV (Poland) & $=6.630$ \\
\hline & ISI (Dubai, UAI & $=0.829$ & РИНЦ (Russia & $=0.156$ & PIF (India) & $=1.940$ \\
\hline & GIF (Australia) & $=0.564$ & ESJI (KZ) & $=8.716$ & IBI (India) & $=4.260$ \\
\hline & JIF & $=1.500$ & SJIF (Morocco & $=5.667$ & OAJI (USA) & $=0.350$ \\
\hline
\end{tabular}

Аннотация: На сегодняшний день, производя один миллион тонн хлопка-волокна, Узбекистан считается шестым крупным государством-производителем. Известно, что и процесс сбора хлопка вручную до приёма его на заводы тоже влияет на качество волокна хлопка. Вследствие этого возникают разные проблемы при переработке хлопка, особенно очищение хлопка от грязи. При наблюдении по очистительной линии УХК (хлопка очистительной агрегат) существующем на заводе, в процессе очищения от грубых и мелких загрязнений, с одной стороны, хлопок почти очищается от загрязнений (положительная сторона существуюших технологий), с другой стороны, наблюдается разделение кусков хлопка на более мелкие части этого куска(отрицательная сторона существующих технологий). Именно такая сторона технологий снижсает качество волокна, не отвечающий сегодняиними требованиями. При этом нами были разработано устройства для очистки хлопка, дающие возможность улучшения качество волокна. Одной особенность этой технологии в том, что из-за потока движения куски хлопка в устройстве направленных сверху вниз, по инериии движения её, ненужные примеси в составе хлопка, двигаясь сверху вниз в проделе сита (метод сепарирование хлопка), быстро выделяются существуюшие грязи и улучшается очищение хлопка. Сетевая поверхность хлопкоочистительного устройства, выполняющая задачу сепаратора, сепарирует поэтапно кусочки семенного хлопка, и через маленькие отверстия сети проходит не хлопок, а загрязнения в его составе. В результате этого осуществляется очистка хлопковых кусков, и сохраняется естественное состояние хлопка, улучшается качество полученного волокна.

Ключевые слова: хлопок; хлопка-сыриа; хирман(стог); качество волокна; хлопкоочистительное устройство; усовершенствование устройства для очистки хлопка; хлопкоочистительные заводы; выбор технологии очищения хлопка; загрязнения семенного хлопка.

\section{Постановка проблемы или Введение.}

За счет поддержки хлопковой политики со стороны государства, Узбекистан занимает одно из ведущих мест в мире по производству и экспорту хлопка. Поэтому в условиях рыночной экономики хлопковая промышленность занимает важное место в экономике страны и в её развитии. На сегодняшний день, производя один миллион тонн хлопка-сырца, Узбекистан считается шестым крупным государством-производителем. Он превратился в ведущего участника мировой хлопковой индустрии[1].

По выводам экспертов в ближайшем будущем ожидается повышение потребления хлопка-сырца в Узбекистане. На сегодняшний день в нашей стране разработана программа развития текстильной и лёгкой промышленности Узбекистана на период до 2020 года. В рамках этой программы намечается повышение десятков проектов инвестиций. Осуществление этих проектов даёт возможность довести степень переработки хлопка-сырца до 80 процентов общего объёма производства и повысить в более три раза экспортный потенциал промышленности Узбекистана.

На основе вышеуказанного разработана концепция и программа развития сферы производства хлопка Республики Узбекистан за 2016-2020 годы. В целях обеспечения выполнения данной программы, выявляется задача определения ряда проблем в данном направлении[2].

Известно, что качество собранного хлопка и волокна, полученного в результате переработки хлопка, зависит от многих факторов. В их числе: своевременный сбор хлопка и его прием на хлопкоочистительный завод, осуществление очистительных работ, удаление загрязненности и влажности до требуемой степени, а также осуществление работ по сохранению. Но, при осуществлении этих работ в сегодняшних условиях, качество волокна, полученного от хлопка, не отвечает требованиям, потому что, вопервых, существующие хлопкоочистительные машины не соответствуют высоким технологиям, во-вторых, сохранение хлопка в хирманах (стогах), его очистка, а также неполадки в передаче хлопка в очистительные машины, влияние других отрицательных факторов.

Именно вышеупомянутые неполадки и другие ставят задачи в повседневную жизнь осуществления модернизации, а также еще более усовершенствование материально-технической базы хлопкоочистительных предприятий. Такие отрицательные факторы, как существование посторонних тяжелых загрязнений (камни, пески и других) в составе хлопка, передаваемого из хирманов, не соответствует требованиям очистительных технологий, в процессе первичной обработки семян хлопка-сырца до попадания их в устройство джинн является основными.

По мнению китайских специалистов, конкурентоспособность и «притягиваемость» хлопка Узбекистана очень низкая. В том числе:

- по характеристике китайских покупателей, в сравнении с другими производителями хлопка, качество волокна нежелательное;

- множество не псов (узелковых волокон) в волокне хлопка;

- существование без волокнистых смесей по причине недостаточной очистки волокна хлопка, и за их счёт качество волокна может не соответствовать требованиям[2].

Методы и способы проведения эксперимента или методологическая база. 


\begin{tabular}{|c|c|c|c|c|c|c|}
\hline \multirow{4}{*}{ Impact Factor: } & ISRA (India) & $=3.117$ & SIS (USA) & $=0.912$ & ICV (Poland) & $=6.630$ \\
\hline & ISI (Dubai, UAI & $=0.829$ & РИНЦ (Russia & $=0.156$ & PIF (India) & $=1.940$ \\
\hline & GIF (Australia) & $=0.564$ & ESJI (KZ) & $=8.716$ & IBI (India) & $=4.260$ \\
\hline & JIF & $=1.500$ & SJIF (Morocco & $=5.667$ & OAJI (USA) & $=0.350$ \\
\hline
\end{tabular}

В хлопкоочистительных заводах в условиях Узбекистана, в том числе, в деятельности Касансайского хлопкоочистительного завода Наманганской области, осуществляются следующие этапы работы:

- сушка в сушильных барабанах хлопкасырца в очистительных цехах 2-СБ-10;

- высушенный хлопок очищается от грубых и мелких загрязнений на очистительной линии УХК;

-очищенный хлопок отделяется от семян в цехах разделения волокна на устройстве 5ДП130(джин);

- полученные волокна прессуются в цехах прессования на устройстве ДБ-1237;

- прессованные волокна взвешиваются на электронных весах и переводятся на склад готовой продукции с помощью ленточного транспортёра;

- отделяя пух от семян на линтерных агрегатах 5ЛП, пух прессуется на устройстве ДА237 ;

- Прессованный пух взвешивается на электронных весах и доставляется на склад готовой продукции. Семена взвешиваются на электронных весах и через элеватор шнеки передаются в склад семян;

При наблюдении нами вышеупомянутых 7 этапов стало известно, что и процесс сбора хлопка вручную до приёма его на заводы тоже влияет на качество волокна хлопка. Как известно, на первых этапах сбора хлопка качество семенного хлопка отвечает указанным требованиям, меньше проблем в его переработке.

Но качество волокна хлопка ухудшается за счет факторов, влияющих на качество волокна на следующих этапах сборов хлопка (осадки, загрязнение собранного хлопка и различные другие факторы). Например, стало известно, что, несмотря на усиление контроля сбора хлопка сборщиками, хлопок имел загрязнения и был сдан на завод.

Вследствие этого возникают разные проблемы при переработке хлопка, особенно на втором этапе (очищение хлопка от грязи). По очистительной линии УХК, в процессе очищения от грубых и мелких загрязнений, с одной стороны, хлопок почти очищается от загрязнений (положительная сторона существующих технологий), с другой стороны, наблюдается разделение кусков хлопка на более мелкие части этого куска (отрицательная сторона существующих технологий). Именно такая сторона технологий снижает качество волокна.

Известно, что существующая коробка хлопка состоит из четырёх кусков, и на каждом куске имеет от 7 до 12 односемянных кусочков хлопка, в общем счете в коробке до 50 семян.

В процессе очищения на устройстве один кусок хлопка семян делится на более мелкие кусочки, т.е. практически на «односемянные кусочки» с волокном. В результате это приводит к уменьшению длины волокна и снижению её качества. В будущем из таких волокон изготавливается ткань, имеющая низкие цены, и на которую спрос на международных рынках почти отсутствует.

\section{Результаты.}

Особое значение имеет правильный выбор технологии очищения хлопка, для получения качественного волокна в предприятиях. Если правильно выбрать технологический процесс производства, в таком случае, уменьшится себестоимость полученной продукции, и расходы на затраченный продукт производства приводят к получению большого дохода.

В результате наблюдений стало известно, что хлопок с высокой степенью загрязнённости быстро сам по себе разогревается, потому что в загрязненном хлопке количество компонентов, временно удерживающих влажность, такие как листья хлопчатника и другие загрязнения, бывает больше чем обычно.

Но, следует утверждать, что очистка загрязнений семенного хлопка (листья хлопчатника, коробочки, земля и другие загрязнения) проводится с помощью существующих традиционных технологий, упомянутых выше. На втором этапе работ, осуществляемых хлопкоочистительными предприятиями, проводится осушение хлопкасырца (с помощью барабанов 2 СБ -10), а в очистительных цехах с помощью очистительной ленты УХК осуществляется очистка от крупных и мелких загрязнений. Но качество хлопка - сырца после этих процессов не отвечает требованиям.

Известно, что при очистке хлопка, собранного при хороших погодных условиях, в хлопкоочистительных предприятиях проблем почти мало (в связи с тем, что процент влажности хлопка отвечает указанным требованиям). Но нормативная влажность в составе хлопка, собранного в условиях дождливой и изменчивой погоды, высокая, тогда качество хлопка снижается, что приводит к снижению производительности труда хлопкоочистительных сооружений. Продукция в рабочем ритме не отвечает требованиям, в резултате, за счёт таких недостаков, ухудшается качество волокна. В свою очередь, это уменьшает количество получаемого волокна. Именно для решения этой проблемы нами было разработано хлопкоочистительное устройство.

С помощью этого устройства можно получить качественное волокно. Намечается повышение степени очистки и воздушности хлопка, а также, улучшение качества волокна[5]. 


\begin{tabular}{|c|c|c|c|c|c|c|}
\hline \multirow{4}{*}{ Impact Factor: } & ISRA (India) & $=3.117$ & SIS (USA) & $=0.912$ & ICV (Poland) & $=6.630$ \\
\hline & ISI (Dubai, UAI & $=0.829$ & РИНЦ (Russia & $=0.156$ & PIF (India) & $=1.940$ \\
\hline & GIF (Australia) & $=0.564$ & ESJI (KZ) & $=8.716$ & IBI (India) & $=4.260$ \\
\hline & JIF & $=1.500$ & SJIF (Morocco & $=5.667$ & OAJI (USA) & $=0.350$ \\
\hline
\end{tabular}

Из Рис. 5 видно, что в хлопкоочистительном устройстве хлопок из хирмана попадает в узел, обеспечивающий движение хлопка(1). Оттуда хлопок, попадая в зубцы валика (80-100мм), овоздушивается, т.е., в результате движений хлопка приводятся в движение загрязнения в нём. Его передают на 1-сетевую поверхность(2), продолжая движение, затем передаётся поочередно на сетевую поверхность следующего этапа $(2,3,4,5,6$-сетевые поверхности). После этого, очищенный и пористый хлопок, попадает в 1-выходную камеру(7) хлопкоочистительного устройства. А затем, отделённые в этом процессе загрязнения через узел устройства, служащего для направления и передачи грязи в специальный защищающий узел(4), выводятся из 2-го выходного отверстия(5).

В сетевых поверхностях устройства, горизонтальные и вертикальные вибрационные движения (под углом 45 градусов) осуществляются с помощью кулачков в форме эллипсоида(6). Сетевая поверхность шарнирно закреплена к устройству(8).

Как наблюдаем из этого опыта, семенной хлопок, попадая в созданное устройство, поочередно проходит через сито (в общем количестве пятикратно проходит через сито). Быль и всякие загрязнения, проходя каждый раз через отверстия сетевой поверхности, выбрасываются через специальные проходы(5).

\section{Обсуждение.}

В этой сфере для улучшения качества хлопкового волокна многими учёными проводится ряд теоретических и практических исследований. Проведённые исследования направлены на предотвращение таких ситуаций, как улучшение качества волокна. В этой связи достойны восхищения теоретические работы ведущих специалистов, узбекских и зарубежных учёных. Изучая процесс очищения различных примесей методом сепарирования или движения семенного хлопка на сетевой поверхности в исследовательских работах, приведены методы удаления существующих загрязнений $[3,4,5,6,7,8,9,10,11]$.

В следующих исследованиях обосновано создание хлопкоочистительного устройства, имеющего барабаны с сетевой поверхностью, разработанного в целях удаления крупных и мелких загрязнений (в зависимости от размера клетки) в состав семенного хлопка, а также улучшение качества хлопкового волокна на 5-7 процентов[12,13,14,15,16].

\section{Заключение.}

Ещё одна особенность этой технологии в том, что из-за потока движения куски хлопка в устройстве направленных сверху вниз, по инерции движения её, ненужные примеси в составе хлопка, двигаясь сверху вниз в проделе сита, быстро выделяются существующие грязи и улучшается очищение хлопка. Вместе с тем улучшается степень пористости хлопка семян, достигается получение из него качественного волокна.

В конце - концов, для улучшения качества волокна нужно очистить по мере возможности, все загрязнения(листья хлопчатника, почвы, пески другие). Такая очистка эффективна только при методе сепарирования, предлагаемого нами, потому что сетевая поверхность хлопкоочистительного устройства, выполняющая задачу сепаратора, сепарирует поэтапно кусочки семенного хлопка, и через маленькие отверстия сети проходит не хлопок, а загрязнения в его составе. В результате этого осуществляется очистка хлопковых кусков, и сохраняется естественное состояние хлопка, улучшается качество полученного волокна[15].

За счёт поочередного сепарирования ещё больше увеличивается степень пористости хлопка, а за счёт натяжки куска хлопка с семян, осуществляется сброс грязи из состава хлопка. Значит, загрязнения в составе хлопка при этой технологии почти удаляются, в результате хлопок c семян улучшается до требуемой степени пористости, сохраняется естественное состояние и качество волокна.

\section{Рекомендации.}

Результаты этого исследования рекомендуются для использования аспирантам, докторантам, студентам и преподавателям в исследовательских работах и интересующимся специалистам в данном направлении.

\section{References:}

1. (2017). Ukaz Prezidenta Respubliki Uzbekistan 07.02.2017 g. UP-4947 «O strategii deystviy po dal'neyshemu razvitiyu Respubliki Uzbekistan» (Sb. zakonadatel'nykh dokumentov Respubliki
Uzbekistan, 2017 g., 6-nomer, 70-stat'ya, 20nomer, 354- stat'ya, 23- nomer, 448- stat'ya, 37nomer, 982- stat'ya). 


\begin{tabular}{|c|c|c|c|c|c|c|}
\hline \multirow{4}{*}{ Impact Factor: } & ISRA (India) & $=3.117$ & SIS (USA) & $=0.912$ & ICV (Poland) & $=6.630$ \\
\hline & ISI (Dubai, UAI & $=0.829$ & РИНЦ (Russia & $=0.156$ & PIF (India) & $=1.940$ \\
\hline & GIF (Australia) & $=0.564$ & ESJI (KZ) & $=8.716$ & IBI (India) & $=4.260$ \\
\hline & JIF & $=1.500$ & SJIF (Morocce & $=5.667$ & OAJI (USA) & $=0.350$ \\
\hline
\end{tabular}

2. (2016). Kontseptsiya razvitiya na 2016-2020 god po promyshlennosti khlopka i masla-zhir $v$ Respublike Uzbekistan, kompaniya kholding «Uzkhlopokeksport». (pp.5-8). Tashkent.

3. Ataullaev, A. K., \& Ravshanov, N. (1989). Issledovaniya protsessa separirovaniya sipuchikh semyan khlopchatnika $i$ rushanki. Moskva, Dep. v viniti, N2035.

4. (2014). Theoretical and Experimental Studies of the effect of incluned Scraper on RAW Cotton from mech Surface. World Journal of Mechanics, USA, 4, pp.371-377. http://dx.doi.org/10.236/wjm.2014.412036

Published Online Desember 2014 in Scires. http://www.scrip.org/journal/wjm

5. Muradov, R. (1993). Separator dlya khlopkasyrtsa, A.S. № 4932076, Byul. №12.

6. Muradov, R., Mamarasulov, K., \& Kozhimerov, S. (1995). Separator dlya khlopka-syrtsa, Patent № 2793 Byul. №3.

7. Muradov, R., \& Obidov, A. (1999). Separator dlya khlopka-syrtsa, Patent №5748, Byul. № 2.

8. Muradov, R. M., Khoshimov, S., \& Dadazhanov, A. (2005). Ustroystvo dlya ochistki khlopka" Gosudarsvennoe patentnoe vedomstvo Respubliki Uzbekistan. Reshenie o vydache patenta na izobretenie zayavka №IAP 2050069, Data podachi zayavki 02.03.2005g.

9. Muradov, R., \& Obidov, A. (2006). Ustroystvo dlya ochistki khlopka , Patent UZ IAP 03227 Byul. № 6 .

10. Muradov, R., Khalimov, M., \& Pirnazarov, A. (2006). Separator dlya khlopka-syrtsa, Patent UZ IAP 03225, Byul. № 6 .

11. Muradov, R. (2007). Usovershenstvovanie konstruktsii oborudovaniya ulavlivaniya tyazhelykh primesey v sostave khlopka. (p.5-9). Tashkent: Akademiya nauk Respubliki Uzbekistan izdatel'stva "Fan".

12. Tadaeva, E., Abdukakhkhorov, Z., Sharifboev, N., \& Ismanov, M. (2013). Issledovanie vibratsionnogo peremeshcheniya khlopka-syrtsa v naklonnoy setchatoy poverkhnosti. FERPI, Nauchnyy - tekhnicheskiy zhurnal, №2, pp.4446.

13. Muradov, R., Karimov, A., \& Tadaeva, E. (2016). Nauchnoe issledovanie o mekhanicheskom vozdeystvii na krupnye i melkie otkhody $\mathrm{v}$ sostave khlopka-syrtsa s semyan. Ferganskiy nauchno-tekhnicheskiy zhurnal FerPI, ITZh, pp.26-33.

14. Tadaeva, E. V., Khamrakulov, A. K., \& Begmatov, D. K. (2016). Razrabotka novoy konstruktsii i tekhnologii setchatogo vrashchayushchegosya chetyrekhbarabannogo ochistitelya khlopka syrtsa ot melkogo sora. Nauchno-tekhnicheskiy zhurnal FerPI, № 4, pp.156-159.

15. Tadaeva, E. V. (2016). Modelirovanie protsessa ochistki dvizhushchegosya po naklonnoy ploskosti sloya khlopka syrtsa ot sornykh primesey. Materialy nauchno-prakticheskoy konferentsii $\mathrm{s}$ nazvaniem «Korporotivnoe sotrudnichestvo proizvotstva i nauka, obrazovanie $\mathrm{V}$ povyshchenie intelektual'noy stepenii tvorchestvo molodezhi”. (pp.210-212). Fergana: FERDU.

16. Tadaeva, E. (2016). Teoreticheskoe izuchenie ochishcheniya khlopka syrtsa mekhanicheskim vliyaniem ot krupnogo i melkogo sora. Nauchno-tekhnicheskiy zhurnal FerPI, № 2, pp.147-150. 